\title{
CT-Quantified Adipose Tissue Distribution: Risk or Protective Factor for Complications after Rectal Cancer Surgery?
}

\author{
Johanna Nattenmüller $^{a}$ Jürgen Böhm ${ }^{b, c}$ Astgik Bagdassarjan ${ }^{a}$ \\ Yakup Kulu $^{d}$ Biljana Gigic c, d Martin Schneider ${ }^{d}$ Hans-Ulrich Kauczor ${ }^{a}$ \\ Cornelia M. Ulrich ${ }^{b, c}$ Alexis Ulrich ${ }^{d, e}$ \\ ${ }^{a}$ Department of Diagnostic and Interventional Radiology, University Hospital Heidelberg, \\ Heidelberg, Germany; ${ }^{b}$ Department of Population Sciences, Huntsman Cancer Institute, Salt \\ Lake City, UT, USA; ' ${ }^{\circ}$ ivision of Preventive Oncology, National Center for Tumor Diseases \\ (NCT) and German Cancer Research Center (DKFZ), Heidelberg, Germany; ${ }^{\mathrm{d}}$ Department of \\ General, Visceral and Transplantation Surgery, University Hospital, Heidelberg, Germany; \\ e Department of Surgery I, Lukas Hospital Neuss, Neuss, Germany
}

\section{Keywords}

Rectal neoplasms - Morbidity · Body composition - Adipose tissue - Obesity paradox . Computed tomography

\begin{abstract}
Purpose: Obesity is associated with increased incidence and mortality in rectal cancer (RC). However, an obesity paradox in the sense of a protective effect of obesity is discussed controversially. We evaluated whether adipose tissue distribution has an impact on medical (MC) and surgical complications (SC) after RC surgery. Methods: A total of 296 RC patients underwent oncological surgery and multidetector $C T$ with quantification of total (TAT), visceral (VAT), and subcutaneous adipose tissue (SAT). Logistic regressions on SC (anastomotic leakage $[n=26]$, wound infection [ $n=58]$, bleeding [ $n=12]$, abscess [ $n=32]$, bladder dysfunction $[n=24]$, burst abdomen [ $n=10]$ ), and MC (pulmonary [ $n=22]$, cardiac $[n=18]$, urinary tract infection $[n=9]$, sepsis $[n=5]$ ) were performed. Results: High pelvic VAT was associated with reduced risk for overall SC (OR $=0.915, p=0.012)$ and anastomotic leakage $(\mathrm{OR}=0.587, p=$
\end{abstract}

Alexis Ulrich, Cornelia M. Ulrich, and Hans-Ulrich Kauczor contributed equally to this work as joint senior authors. 
Nattenmüller et al.: The Obesity Paradox

0.024, Cl: 0.369/0.934). In contrast, CT-quantified obesity was associated with increased risk for wound infection, bladder dysfunction, burst abdomen, overall MC, and cardiac complications (ORs up to 1.423). BMI was not associated with any SC or MC. Conclusion: An obesity paradox with a protective effect of CT-quantified adipose tissue was confirmed for anastomotic leakage and overall SC. In contrast, high adipose tissue was associated with higher risk for other SC and MC. These results show a more complex influence of body composition on MC and SC. CT-quantified obesity is able to provide deeper insights to explain the obesity paradox beyond BMI.

(C) 2019 The Author(s)

Published by S. Karger AG, Basel

\section{Introduction}

Overweight and obesity are important global health problems associated with increased incidence and morbidity for various diseases [1-3], resulting in an increased all-cause mortality [4,5]. Recently, conflicting observations have been reported, with a survival advantage for obese and disadvantage in underweight and even normal-weight individuals in specific populations with chronic diseases, described as the so-called obesity paradox [68]. This phenomenon was first described in patients on hemodialysis, and later in patients with chronic heart failure, hypertension, coronary artery disease, and type 2 diabetes [8-11]. Chronic diseases aside, in 2008, Mullen et al. [12] showed the highest 30-day mortality for underweight patients in a prospective study of 2,258 patients with major abdominal surgery. In 2009, Mullen et al. [13] confirmed the obesity paradox in a larger prospective cohort with 118,707 individuals undergoing nonbariatric surgery, showing the highest 30 -day mortality in underweight and severely obese and the lowest mortality in overweight and moderately obese patients, corresponding to a reverse J-shaped mortality curve.

Rectal cancer (RC) is one of the most common cancer types [14]. Several studies showed that overweight and obesity are associated with increased incidence of RC $[2,15]$. Obesity is also associated with an increased risk of recurrence and mortality $[16,17]$. Because of increased incidence and mortality of RC in obese individuals on the one hand and the obesity paradox on the other, the role of overweight and obesity in RC still seems contradictory. One reason for conflicting results might be that the majority of studies investigating the obesity paradox were based on BMI [18]. However, BMI lacks a differentiation between muscle and fat mass, or between visceral (VAT) and subcutaneous (SAT) adipose tissue. Therefore, additional studies using methods that more accurately reflect body composition, and specifically adipose tissue distribution, are needed to understand the complex influence of obesity in RC.

This study aims to investigate the influence of obesity on morbidity after RC surgery by analyzing surgical (SC) and medical complications (MC) and their association with CT-quantified adipose tissue distribution in addition to body weight and BMI.

\section{Materials and Methods}

Patient Characteristics

A total of 296 patients who underwent RC surgery at our institution between January 2008 and May 2013 were retrospectively enrolled in this study. Patients were consecutively selected by analyzing lists of RC surgery from this institution with review of their charts. Eligibility criteria were: primary diagnosis of RC, procedure of surgery for RC, age $\geq 18$ years and availability of a CT scan within 180 days from the date of 
Table 1. Characteristics of the study population $(\mathrm{n}=296)$
Nattenmüller et al.: The Obesity Paradox

\begin{tabular}{|c|c|}
\hline Age, mean $\pm S D$, years & $63.7 \pm 11.9$ \\
\hline \multicolumn{2}{|l|}{ Sex, $n(\%)$} \\
\hline Male & $210(71)$ \\
\hline Female & $86(29)$ \\
\hline \multicolumn{2}{|l|}{ BMI } \\
\hline Mean (SD) & $26(4.2)$ \\
\hline $\operatorname{Min} / \max$ & $16 / 40$ \\
\hline Underweight (BMI < 18.5), $n$ (\%) & $10(3.4)$ \\
\hline Normal weight (BMI 18.5-24.99), $n$ (\%) & $116(39.2)$ \\
\hline Overweight (BMI 25-29.99), $n(\%)$ & $119(40.2)$ \\
\hline Obese Class I-III (BMI $\geq 30), n(\%)$ & $51(17.2)$ \\
\hline \multicolumn{2}{|l|}{ Diabetes mellitus status, $n(\%)$} \\
\hline Yes & $49(16.4)$ \\
\hline No & $247(83.6)$ \\
\hline \multicolumn{2}{|c|}{ Preoperative fasting glucose level at day of surgery } \\
\hline Mean \pm SD & $139.3 \pm 33$ \\
\hline $\operatorname{Min} / \max$ & $71 / 313$ \\
\hline \multicolumn{2}{|l|}{ UICC stage, $n(\%)$} \\
\hline 0 & $5(1.7)$ \\
\hline I & $67(22.6)$ \\
\hline II & $75(25.3)$ \\
\hline III & $97(32.8)$ \\
\hline IV & $52(17.6)$ \\
\hline \multicolumn{2}{|l|}{ Type of surgery } \\
\hline LAR, $n(\%)$ & $228(77.0)$ \\
\hline HAR, $n(\%)$ & $12(4.1)$ \\
\hline $\mathrm{APR}, n(\%)$ & $49(16.6)$ \\
\hline PE, $n(\%)$ & $6(2.0)$ \\
\hline Other, $n(\%)$ & $1(0.3)$ \\
\hline \multicolumn{2}{|l|}{ Stoma, $n(\%)$} \\
\hline Yes & $283(95.6)$ \\
\hline No & $13(4.4)$ \\
\hline \multicolumn{2}{|l|}{ Height of rectal cancer } \\
\hline Low rectal cancer $(\leq 5 \mathrm{~cm})$ & $109(36.8)$ \\
\hline High rectal cancer $(\geq 6 \mathrm{~cm})$ & $165(55.7)$ \\
\hline Missing & $22(7.4)$ \\
\hline \multicolumn{2}{|l|}{ Neoadjuvant radiotherapy } \\
\hline Yes & $180(60.8)$ \\
\hline No & $112(37.8)$ \\
\hline Missing & $4(1.4)$ \\
\hline \multicolumn{2}{|l|}{ Time of CT scan } \\
\hline CT scans pre-surgery, $n$ & 217 \\
\hline Time, mean (SD), days & $27.99(31.7)$ \\
\hline Min/max, days & $1 / 174$ \\
\hline CT scans post-surgery, $n$ & 79 \\
\hline Time, mean (SD), days & $35.3(40.2)$ \\
\hline Min/max, days & $2 / 171$ \\
\hline \multicolumn{2}{|l|}{ Radiation exposure } \\
\hline \multicolumn{2}{|l|}{ DLP, mGy cm } \\
\hline Median & 603 \\
\hline Q1/Q3 (interquartile range) & $400 / 786$ \\
\hline \multicolumn{2}{|l|}{ Effective tube current-time product, mAs } \\
\hline Median & 145 \\
\hline
\end{tabular}


Nattenmüller et al.: The Obesity Paradox

Table 1 (continued)

\begin{tabular}{lc}
\hline Q1/Q3 (interquartile range) & $114 / 176.5$ \\
X-Ray tube voltage, $\mathrm{kV}$ & 120 \\
Median & $120 / 120$ \\
Q1/Q3 (interquartile range) & \\
\hline Duration of surgery, min & $247.1(89.7)$ \\
Mean time (SD) & $100.0 / 720.0$ \\
Min/max & $19(19.0)$ \\
\hline Hospital stay duration (days) & $2 / 218$ \\
Mean (SD) & \\
Min/Max & \\
\hline \multicolumn{2}{l}{ BMI, body mass index; SD, standard deviation; LAR, low anterior } \\
rectum resection; HAR, high anterior rectum resection; APR, \\
abdominoperineal resection; PE, pelvic exenteration.
\end{tabular}

Fig. 1. Area-based quantification of total adipose tissue (b; pink color) and visceral adipose tissue (c; pink color) at the L3/4 spinal level (a; level of measurements indicated by the blue line) of a male patient aged 59 years.
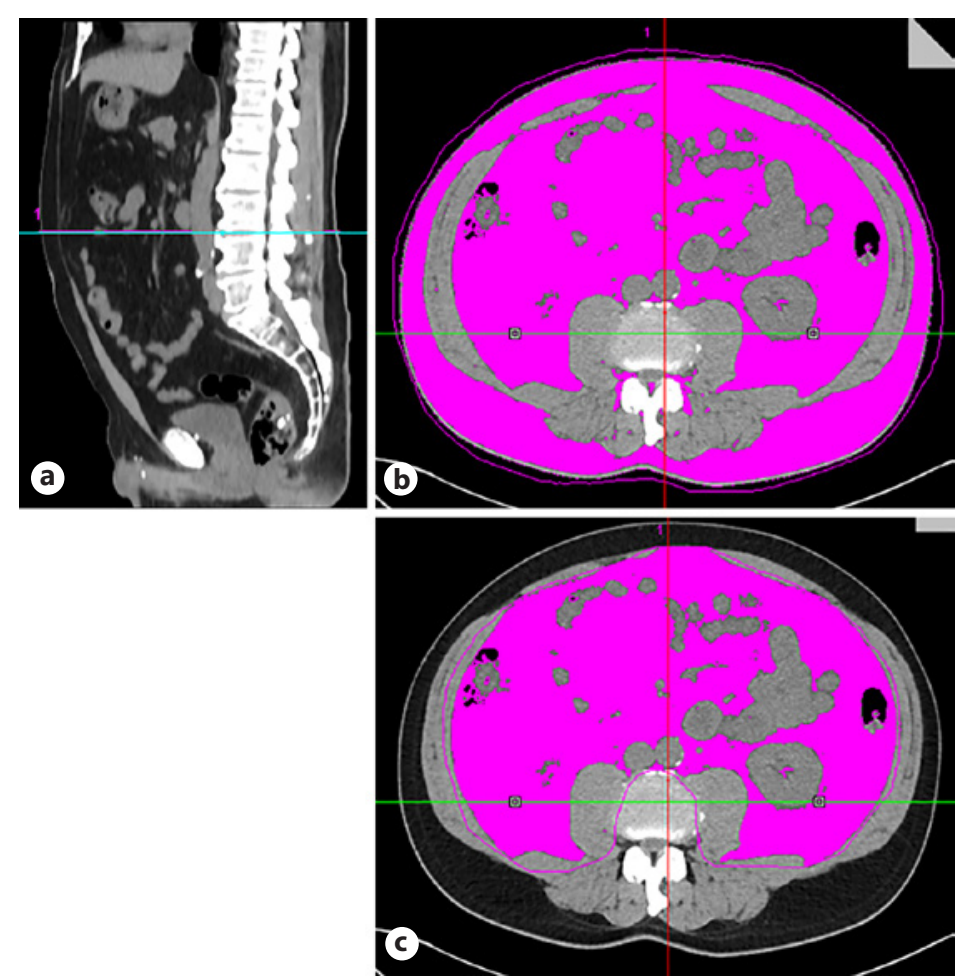

surgery. We retrospectively retrieved abdominal CT scans using the institutional PACS (GE Medical Systems, Little Chalfont, UK). Data on diagnosis, date of surgery, Union for International Cancer Control (UICC) classification and location of tumor, age, sex, height, weight (derived from the anesthesia protocol the day before surgery), BMI, diabetes status, preoperative fasting glucose levels, duration of surgery, type of surgery, length of hospital stay, amount of blood loss, MC (cardiac, pulmonary, sepsis, urinary tract infection [UTI]) and SC during hospital stay (anastomotic leakage, wound infection, bleeding, abscesses, bladder dysfunction, burst abdomen); and presence-status of stoma were abstracted from the hospital information system I.S.-H.*med. (SAP, Walldorf, Germany). For detailed patient characteristics, see Table 1. 

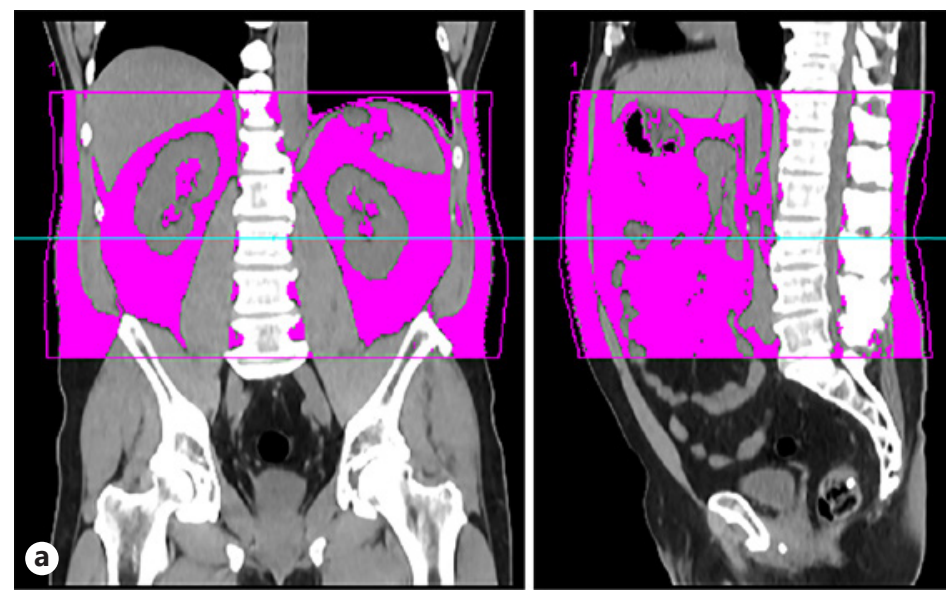

Fig. 2. Volume-based quantification of abdominal total adipose tissue (a) and visceral adipose tissue (b) at the Th11/12 to S1 spinal level (adipose tissue marked in pink) of a male patient aged 59 years.
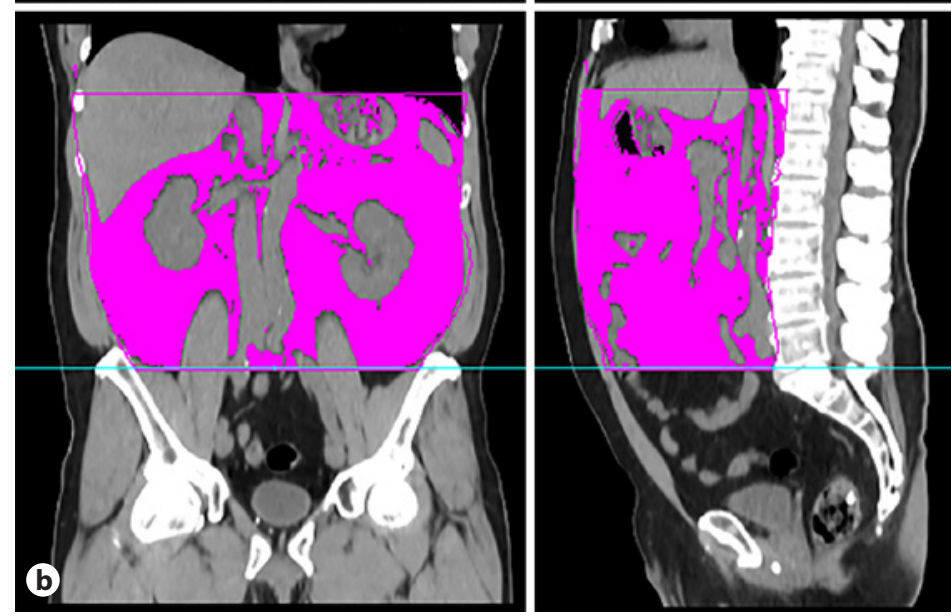

CT-Based Quantification of Adipose Tissue

Densitometric quantification based on CT scans was performed using a postprocessing software tool (MMPW, CT Volume tool, Siemens Healthcare, Erlangen, Germany). First, area-based quantification of adipose tissue compartments was performed on the L3/4 spinal level (volumetric quantification of selected slice, divided by slice thickness, unit: $\mathrm{cm}^{2}$ ) [19-21] (Fig. 1). Additionally, volumetric measurements (unit: $\mathrm{cm}^{3}$ ) of the abdominal (Th11/12 to L5/S1 spinal level, Fig. 2) and pelvic adipose tissue (level S1 to upper edge of symphysis, Fig. 3) were performed. Specific regions of interest were manually determined: total adipose tissue (TAT; whole abdominal circumference, see Fig. 1-3) and VAT (by defining the fascial plane of the abdominal muscle wall) were measured. Limits of measurements for selecting specifically adipose tissue were -190 to $-30 \mathrm{HU}[22,23]$. SAT was calculated by subtracting VAT from TAT [21]. The visceral-to-subcutaneous fat ratio was calculated as VAT/SAT at level L3/4.

\section{Statistical Analysis}

Data were managed using a spreadsheet program (Microsoft Office Excel ${ }^{\circledR} 2010$, Microsoft Corporation, Redmond, WA, USA). Descriptive and statistical analyses were performed using SAS 9.3 (2008, SAS Institute, Cary, NC, USA). Logistic regressions for the impact of adipose tissue on MC and SC were applied. Additionally, multivariate logistic regression models adjusted for age and sex were performed (online suppl. Table 1 and 2; for all online suppl. material, see www.karger.com/doi/10.1159/000499320). Pearson correlations for length of hospital stay, time of surgery, and blood loss with adipose tissue were assessed. All analyses had a statistical power of $\sim 90 \%$ and were considered significant at $\alpha=0.05$. 
Fig. 3. Volume-based quantification of pelvic total adipose tissue (a) and visceral adipose tissue (b) at the level of vertebral body S1 to symphysis (adipose tissue marked in pink) of a male patient aged 59 years.
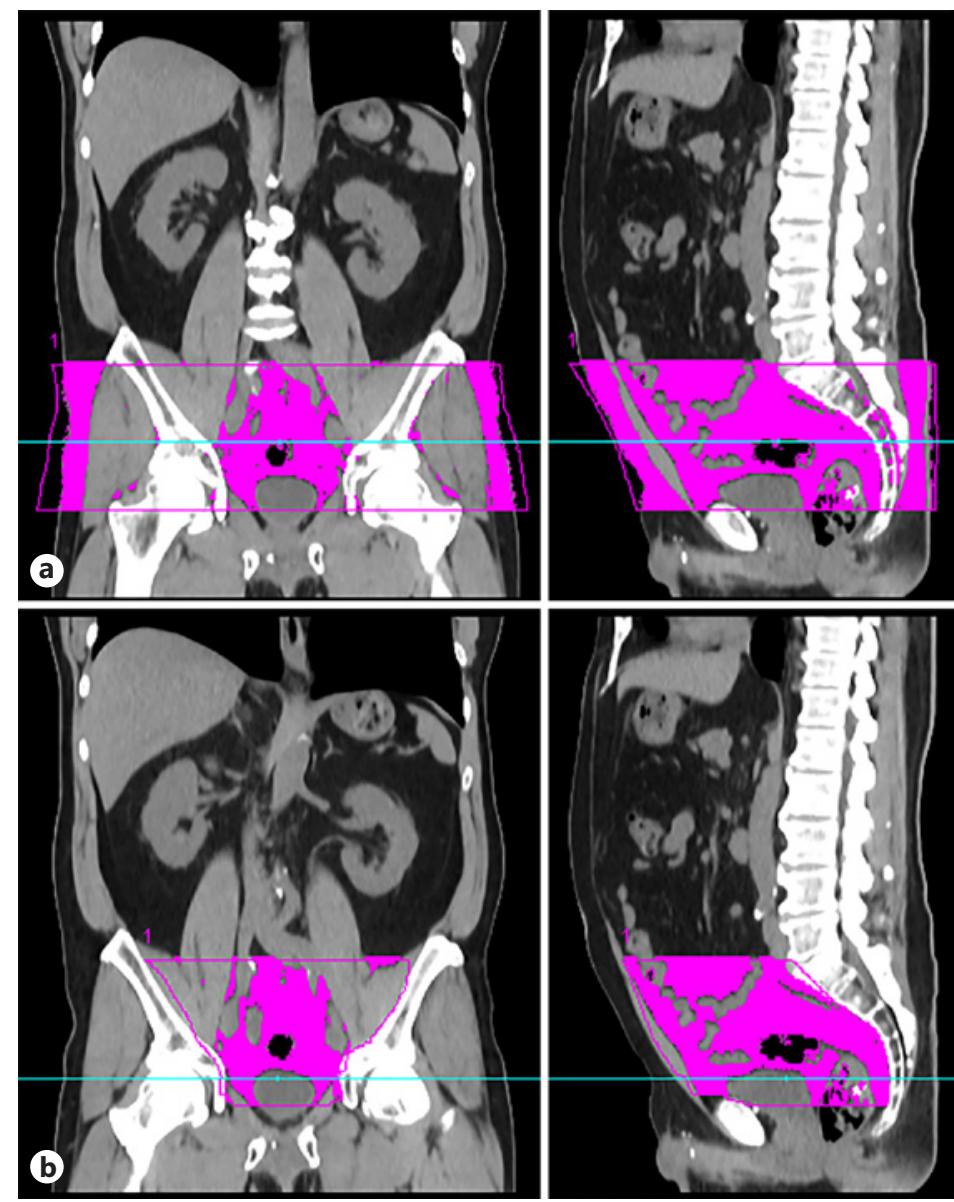

\section{Results}

\section{Distribution of Adipose Tissue}

Detailed characteristics of the overall study population, including cancer stages and surgical procedures performed, are provided in Table 1 . Mean values and standard deviations of TAT, VAT, SAT, and VAT/SAT at the L3/4 spinal level, resulting from area-based quantification, are provided in Table 2. Volume-based measurements of abdominal and pelvic TAT, VAT, and SAT are provided in Table 2.

\section{Frequency of SC and MC}

Within the patient cohort of 296 patients, 103 subjects developed at least one surgical complication during their hospital stay (34.8\%). Out of these, wound infection was most frequent with 58 cases $(19.9 \%)$, followed by abscess with 32 cases $(10.8 \%)$. Anastomotic leakage occurred in 26 out of 240 patients with anastomosis. Furthermore, 24 patients $(8.1 \%)$ suffered bladder dysfunction, 12 (4.1\%) patients bleeding, and 10 patients (3.4\%) burst abdomen (Table 3). MC occurred in 48 out of 296 patients during their hospital stay $(16.2 \%)$. Most common were pulmonary complications with 22 cases $(7.4 \%)$, followed by cardiac complications in 18 cases (6.1\%). UTI occurred in 9 cases $(3.0 \%)$ and sepsis or systemic inflammatory response syndrome (SIRS) in 5 cases (1.7\%) (Table 3). 
Nattenmüller et al.: The Obesity Paradox

Table 2. Distribution of adipose tissue across compartments by area and volume $(n=296)$

\begin{tabular}{|c|c|c|c|c|}
\hline \multirow[t]{2}{*}{ Level of quantification } & \multicolumn{4}{|c|}{ Adipose tissue compartments } \\
\hline & TAT & VAT & SAT & VAT/SAT \\
\hline \multicolumn{5}{|l|}{$\mathrm{L} 3 / 4$} \\
\hline Mean area, $\mathrm{cm}^{2}$ & 371.2 & 175.4 & 199.8 & 0.94 \\
\hline SD & 155.0 & 90.9 & 93.1 & 0.49 \\
\hline Female mean area, $\mathrm{cm}^{2}$ & 345.1 & 126.4 & 229.6 & 0.54 \\
\hline SD & 162.2 & 73.8 & 112.4 & 0.32 \\
\hline Male mean area, $\mathrm{cm}^{2}$ & 380.5 & 195.5 & 189.2 & 1.09 \\
\hline SD & 151.8 & 89.8 & 83.0 & 0.46 \\
\hline \multicolumn{5}{|l|}{ Volume abdomen } \\
\hline Mean volume, $\mathrm{cm}^{3}$ & $6,437.6$ & $3,201.0$ & $3,278.9$ & - \\
\hline SD & $2,887.5$ & $1,622.4$ & $1,558.7$ & - \\
\hline Female mean area, $\mathrm{cm}^{2}$ & $5,229.1$ & $2,107.5$ & $3,543.7$ & \\
\hline SD & $2,496.6$ & $1,139.2$ & $1,757.1$ & \\
\hline Male mean area, $\mathrm{cm}^{2}$ & $6,750.9$ & $3,640.6$ & $3,210.2$ & \\
\hline SD & $2,909.5$ & $1,581.3$ & $1,504.4$ & \\
\hline \multicolumn{5}{|l|}{ Volume pelvis } \\
\hline Mean volume, $\mathrm{cm}^{3}$ & $3,036.9$ & 918.4 & $2,165.6$ & \\
\hline SD & $1,353.8$ & 374.7 & $1,123.0$ & - \\
\hline Female mean area, $\mathrm{cm}^{2}$ & $3,576.1$ & 874.8 & $2,840.6$ & \\
\hline SD & $1,486.5$ & 634.6 & $1,284.5$ & \\
\hline Male mean area, $\mathrm{cm}^{2}$ & $2,897.1$ & 936.0 & $1,990.7$ & \\
\hline SD & $1,288.0$ & 378.2 & $1,012.2$ & \\
\hline
\end{tabular}

SD, standard deviation; TAT, total adipose tissue; VAT, visceral adipose tissue; SAT, subcutaneous adipose tissue; VAT/SAT, visceral fat ratio VAT/SAT.

Table 3. Incidence of surgical and medical complications after rectal cancer surgery $(n=296)$

\begin{tabular}{lc}
\hline Type of complication & $n(\%)$ \\
\hline Surgical (overall) & $103(34.8)$ \\
Surgical complications (descending order) & $58(19.9)$ \\
$\quad$ Wound infection & $32(10.8)$ \\
Abscess & $26(10.8)$ \\
Anastomotic leakage $(n=240)^{\mathrm{a}}$ & $24(8.1)$ \\
Bladder & $12(4.1)$ \\
Bleeding & $10(3.4)$ \\
Burst abdomen & $48(16.2)$ \\
\hline Medical (overall) & $22(7.4)$ \\
Medical complications (descending order) & $18(6.1)$ \\
Pulmonary & $9(3.0)$ \\
Cardiac & $5(1.7)$ \\
$\quad$ Urinary tract infection & \\
\hline Sepsis/SIRS & \\
\hline a Out of 240 patients with anastomosis. & \\
\hline
\end{tabular}


Nattenmüller et al.: The Obesity Paradox

Table 4. Logistic regression of adipose tissue compartments on surgical complications, $n=296$ (total), for anastomotic leakage, $n=240$ (patients with anastomosis)

\begin{tabular}{|c|c|c|c|c|}
\hline Type of complication & $\begin{array}{l}\text { Adipose tissue } \\
\text { compartment }\end{array}$ & OR & $\begin{array}{l}\text { Confidence } \\
\text { interval }\end{array}$ & $\begin{array}{l}p \text { value } \\
\left(\chi^{2}\right)\end{array}$ \\
\hline $\begin{array}{l}\text { Surgical complications (total) } \\
\text { Anastomotic leakage } \\
\text { Wound infection } \\
\text { Bleeding } \\
\text { Abscess }\end{array}$ & $\begin{array}{l}\text { VAT }_{\text {pelvis }} \\
\text { VAT }_{\text {pelvis }} \\
\text { SAT }_{\text {pelvis }} \\
\text { TAT }_{\text {pelvis }}{ }^{\mathrm{I}} \\
\text { none } \\
\text { none }\end{array}$ & $\begin{array}{l}0.915 \\
0.587 \\
1.138 \\
1.106\end{array}$ & $\begin{array}{l}0.854 / 0.981 \\
0.369 / 0.934 \\
1.015 / 1.275 \\
1.002 / 1.22\end{array}$ & $\begin{array}{l}0.012 \\
0.024 \\
0.027 \\
0.046\end{array}$ \\
\hline Bladder dysfunction & $\begin{array}{l}\text { TAT }_{\text {abd }}{ }^{\mathrm{I}} \\
\mathrm{VAT}_{\text {abd }} \mathrm{I} \\
\mathrm{VAT}_{\mathrm{L} 3 / 4}{ }^{\mathrm{I}} \\
\mathrm{TAT}_{\text {abd }}{ }^{\mathrm{I}} \\
\mathrm{VAT}_{\text {abd }} \mathrm{I} \\
\mathrm{SAT}_{\text {abd }}{ }^{\mathrm{I}} \\
\mathrm{TAT}_{\text {pelvis }}{ }^{\mathrm{I}} \\
\mathrm{SAT}_{\text {pelvis }}{ }^{\mathrm{I}} \\
\mathrm{TAT}_{\mathrm{L} 3 / 4}{ }^{\mathrm{I}} \\
\mathrm{VAT}_{\mathrm{L} 3 / 4}{ }^{\mathrm{I}}\end{array}$ & $\begin{array}{l}1.118 \\
1.196 \\
1.157 \\
1.321 \\
1.336 \\
1.423 \\
1.354 \\
1.365 \\
1.135 \\
1.257\end{array}$ & $\begin{array}{l}1.00008 / 1.249 \\
1.015 / 1.409 \\
1.009 / 1.326 \\
1.097 / 1.591 \\
1.052 / 1.697 \\
1.089 / 1.86 \\
1.12 / 1.648 \\
1.112 / 1.677 \\
1.01 / 1.275 \\
1.029 / 1.536\end{array}$ & $\begin{array}{l}0.0498 \\
0.032 \\
0.036 \\
0.003 \\
0.017 \\
0.01 \\
0.003 \\
0.003 \\
0.033 \\
0.025\end{array}$ \\
\hline
\end{tabular}

TAT, total adipose tissue; VAT, visceral adipose tissue; SAT, subcutaneous adipose tissue; abd, abdominal volume TH11/12to L5/S1; pelvis, pelvic volume S1-upper edge symphysis; L3/4, lumbar vertebra level L3/ L4. Odds ratios and corresponding confidence intervals were scaled to reflect a change of 10 units for body size-adjusted values (I), a change of 50 units $\left(\mathrm{cm}^{2}\right)$ for adipose tissue area L3/4, a change of 100 units $\left(\mathrm{cm}^{3}\right)$ for volume-based adipose tissue parameters, and a change of 0.1 units for VAT/SAT. ${ }^{\mathrm{I}}$ Index after adjustment of value for body size $\left(\mathrm{cm}^{2} / \mathrm{m}^{2}\right)$ or $\left(\mathrm{cm}^{3} / \mathrm{m}^{2}\right)$.

Significance of Adipose Tissue Compartments Concerning SC

High amounts of pelvic VAT were associated with a decreased risk for overall SC $(\mathrm{OR}=$ $0.915, p=0.012$, CI: $0.854 / 0.981$ ) and a lower risk for anastomotic leakage (OR $=0.587$, $p=0.024$, CI: $0.369 / 0.934)$. By contrast, high amounts of pelvic SAT and TAT were associated with a higher risk for wound infections (SAT: OR $=1.138, p=0.027$; TAT: OR $=1.106$, $p=0.046)$. Moreover, high abdominal VAT and TAT values were associated with a higher risk for bladder dysfunction (TAT: OR $=1.118, p=0.0498$; VAT: OR $=1.196, p=0.032$ ). Similarly, high amounts of all pelvic and abdominal adipose tissue compartments (TAT, VAT, and SAT) were associated with an increased risk for burst abdomen (OR: from 1.135 to 1.423; $p<0.033$ ) (Table 4). Regarding bleeding and abscesses, no association with the extent of adipose tissue was found. There was also no significant impact of BMI or overall body weight on all above-mentioned types of complications (nonsignificant results not shown). After adjusting for sex and age in the multivariate logistic regression, the above described results remained significant with exceptions of TAT in wound infection and bladder dysfunction and VAT in burst abdomen and bladder dysfunction (online suppl. Table 1).

\section{Significance of Adipose Tissue Compartments Concerning MC}

High amounts of abdominal and pelvic TAT and SAT were associated with a higher risk for overall MC (OR: from 1.11 to 1.193, $p<0.032$ ). In particular, patients with high amounts of pelvic and abdominal TAT, VAT, and SAT showed an increased risk for cardiac complications 
Nattenmüller et al.: The Obesity Paradox

Table 5. Logistic regression of adipose tissue compartments on medical complications $(n=296)$

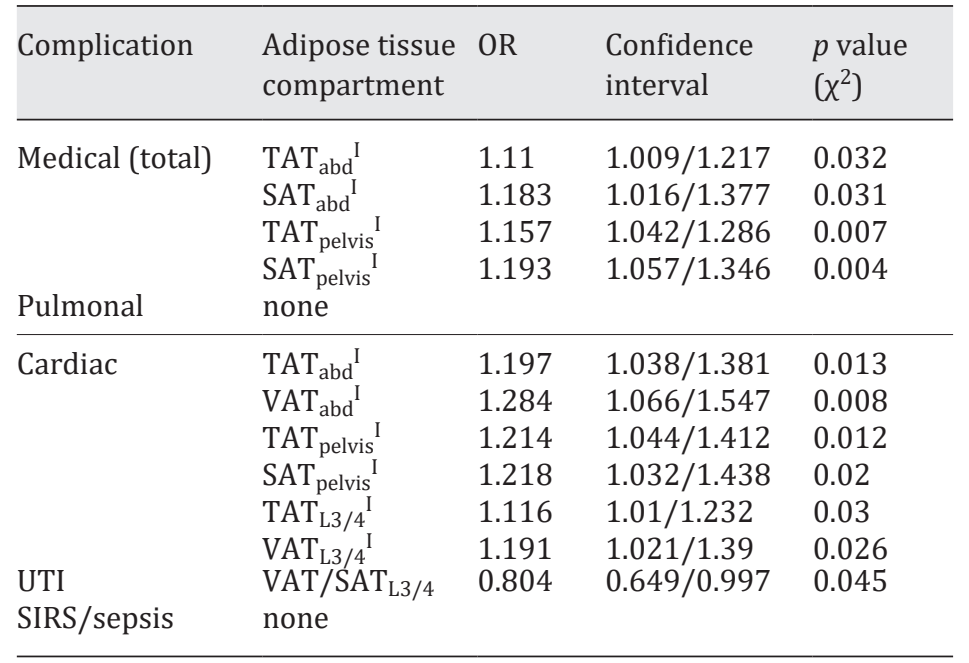

TAT, total adipose tissue; VAT, visceral adipose tissue; SAT, subcutaneous adipose tissue; abd, abdominal. Odds ratios and corresponding confidence intervals were scaled to reflect a change of 10 units for body size-adjusted values (I), a change of 50 units $\left(\mathrm{cm}^{2}\right)$ for adipose tissue area $\mathrm{L} 3 / 4$, a change of 100 units $\left(\mathrm{cm}^{3}\right)$ for volume-based adipose tissue parameters and a change of 0.1 units for VAT/SAT. ${ }^{\mathrm{I}}$ Index after adjustment of value for body size $\left(\mathrm{cm}^{2} / \mathrm{m}^{2}\right)$ or $\left(\mathrm{cm}^{3} / \mathrm{m}^{2}\right)$.

(OR: from 1.116 to $1.284, p<0.031$ ). A high ratio of VAT/SAT was associated with a reduced risk for UTI (OR $=0.084, p=0.045$ ) (Table 5). There was no significant association of pulmonary complications or SIRS/sepsis with adipose tissue values. Similar to SC, BMI and body weight alone did not correlate with the risk for MC (nonsignificant results not shown). Taken together, except UTI no obesity paradox was detectable concerning MC. After adjusting for sex and age in the multivariate logistic regression, the above-described results remained significant with exceptions of VAT/SAT in UTI and $\mathrm{VAT}_{\mathrm{L} 3 / 4}$ in cardiac complications (online suppl. Table 2).

\section{Localization of $R C$ and Diabetes Status}

There were no statistically significant differences of anastomotic leakages between low and high RC using a Fisher's exact test (results not shown). Thus, no further stratifications were done.

We did not observe any statistically significant differences in complications with respect to the diabetes mellitus status using a Fisher's exact test. Also, there were no significant differences in complications with respect to the preoperative fasting glucose levels measured on the day of surgery using a Kruskal-Wallis test (nonsignificant results not shown).

\section{Length of Hospital Stay, Duration of Surgery, Blood Loss}

High pelvic SAT ( $r=0.21$ ) was positively correlated with the length of hospital stay. Comparable correlations with the duration of hospitalization did not exist concerning BMI or total body weight (Table 6). Concerning duration of surgery, BMI $(r=0.22)$ and body weight $(r=0.165)$ were positively correlated with operating times. Regarding adipose tissue, L3/4 TAT $(r=0.156)$, abdominal VAT ( $r=0.147)$, and L3/4 SAT $(r=0.157)$ were likewise positively correlated with duration of surgical procedures (Table 6). Blood loss during surgery was not significantly correlated with any adipose tissue compartment, or with weight or BMI (Table 6). Thus, no obesity paradox was detectable concerning length of hospital stay, duration of surgery, or quantity of blood loss. 
Nattenmüller et al.: The Obesity Paradox

Table 6. Pearson correlations of hospital stay duration, operation duration, and blood loss with BMI, weight, and adipose tissue compartments

\begin{tabular}{|c|c|c|c|}
\hline & $\begin{array}{l}\text { Hospital } \\
\text { duration } \\
r(p)\end{array}$ & $\begin{array}{l}\text { Operation } \\
\text { duration } \\
r(p)\end{array}$ & $\begin{array}{l}\text { Blood loss } \\
r(p)\end{array}$ \\
\hline BMI & $0.022(0.7)$ & $0.22(0.0001)^{*}$ & $0.069(0.26)$ \\
\hline Weight & $0.053(0.36)$ & $0.165(0.004)^{*}$ & $0.024(0.7)$ \\
\hline $\mathrm{TAT}_{\mathrm{abd}}{ }^{\mathrm{I}}$ & $0.112(0.19)$ & $0.159(0.066)$ & $0.031(0.743)$ \\
\hline $\mathrm{TAT}_{\text {pelv }}{ }^{\mathrm{I}}$ & $0.158(0.06)$ & $0.147(0.08)$ & $0.03(0.746)$ \\
\hline $\mathrm{TAT}_{\mathrm{L} 3 / 4}{ }^{\mathrm{I}}$ & $0.043(0.49)$ & $0.156(0.01)^{*}$ & $-0.07(0.29)$ \\
\hline $\mathrm{VAT}_{\mathrm{abd}} \mathrm{I}^{\mathrm{T}}$ & $0.084(0.16)$ & $0.147(0.01)^{*}$ & $-0.007(0.91)$ \\
\hline VAT $_{\text {pelv }}{ }^{\mathrm{I}}$ & $0.066(0.27)$ & $0.092(0.122)$ & $-0.052(0.42)$ \\
\hline $\operatorname{VAT}_{\mathrm{L} 3 / 4}{ }^{\mathrm{I}}$ & $0.078(0.18)$ & $0.12(0.04)^{*}$ & $-0.043(0.484)$ \\
\hline $\mathrm{SAT}_{\mathrm{abd}} \mathrm{I}$ & $0.134(0.12)$ & $0.115(0.18)$ & $0.014(0.884)$ \\
\hline $\mathrm{SAT}_{\text {pelv }}{ }^{\mathrm{I}}$ & $0.21(0.01)^{*}$ & $0.123(0.15)$ & $0.031(0.742)$ \\
\hline $\mathrm{SAT}_{\mathrm{L} 3 / 4}{ }^{\mathrm{I}}$ & $0.023(0.72)$ & $0.157(0.012)^{*}$ & $-0.048(0.472)$ \\
\hline $\mathrm{VAT} \mathrm{SAT}_{\mathrm{L} 3 / 4}$ & $0.016(0.8)$ & $-0.008(0.89)$ & $0.0002(0.98)$ \\
\hline
\end{tabular}

$\alpha=0.5, n$ (total) $=296,{ }^{*} p<0.05$, significant. BMI, body mass index; TAT, total adipose tissue; VAT, visceral adipose tissue; SAT, subcutaneous adipose tissue; abd, abdominal volume TH11/12 to L5/S1; pelvis, pelvic volume S1-upper edge symphysis; L3/4, lumbal vertebra L3/L4 level. ${ }^{I}$ Index after adjustment of value for body size $\left(\mathrm{cm}^{2} / \mathrm{m}^{2}\right)$.

\section{Discussion}

This retrospective study investigated the obesity paradox in post-surgery morbidity of $\mathrm{RC}$ patients in order to differentiate effects of body composition of adipose tissue beyond BMI on surgical and medical complications.

Regarding adipose tissue and SC, an obesity paradox was confirmed, showing a protective impact of increased pelvic adipose tissue on anastomotic leakage, which was also apparent after adjustment for age and sex. This effect may reflect a mechanical protection of the anastomosis by the surrounding adipose tissue. We also found a protective effect of high pelvic adipose tissue on overall surgical complications, which might be due to anastomotic leakages being one of the most common complications in our patient cohort with 26 cases.

The obesity paradox, however, was not detectable concerning any other type of surgical complication. In contrast, high amounts of adipose tissue yielded a higher risk of wound infection, which is in line with previous studies, and likely due to delayed or impaired wound healing in patients with thick SAT layers $[12,13,24,25]$, or possible comorbidity with diabetes mellitus. Bladder dysfunctions were likewise associated with high amounts of VAT and TAT, which could be caused by more complex technical conditions during surgery, prompted by reduced visibility and impaired exposure of the fat-containing pelvis. The risk for burst abdomen was likewise increased with higher amounts of all adipose tissue compartments (VAT, SAT, and TAT), probably due to increased intraabdominal pressure, impairment of wound healing and more complex surgical conditions. BMI alone, however, showed no influence regarding any of the surgical complications mentioned above, which is on par with other studies [26].

Regarding MC, high amounts of adipose tissue were associated with increased overall occurrence of MC (in case of SAT and TAT), and increased cardiac complications (in case of TAT, VAT, SAT). Consistent with this finding, Lopez-Delgado et al. [27] showed an increase in cardiac complications (myocardial infarction) following cardiac surgery in obese patients (characterized by BMI). There was, however, no association between adipose tissue mass and pulmonary 
complications or sepsis/SIRS in our present study. This differs from previous findings by LopezDelgado et al. [27], who detected increased rates of septicemia after cardiac surgery in the obese. Again, BMI alone had no significant influence on MC in our study population.

Increased adipose tissue compartments, but not BMI or body weight, were positively correlated with the length of hospital stay, which was also seen by Tsujinaka et al. [25], Chern et al. [29], and Heus et al. [28], who also observed a prolonged hospital stay in obese. Regarding surgery duration, weight, BMI, and all adipose tissue compartments were positively correlated, probably due to aggravated surgical conditions with reduced visibility. This was also seen by Tsujinaka et al. [25] and Chern et al. [29], who also observed a prolonged surgery duration in obese. There was no significant correlation of blood loss with any adipose tissue compartment as well as weight or BMI. In contrast, in a study by Heus et al. [28], high VAT was associated with high perioperative blood loss.

Overall, in our study we detected both protective and negative effects of adiposity regarding SC and MC after RC surgery. Interestingly, BMI and body weight alone showed mostly no influence, while exact fat distributions as measured by CT did clearly (both positively and negatively) correlate with various complications. However, in the vast majority of 42 studies conducted in 2014, the obesity paradox was defined by BMI $(n=31)$, followed by other surrogate metrics $(n=7)$, and only a minority of 4 studies used methods reflecting the body composition more exactly [18]. This underlines that BMI, which is used as the mainstay in most studies concerning the obesity paradox, is probably not a sufficiently reliable tool for estimating the effects of body composition on surgical outcomes. Some of the conflicting results, obtained in previous studies applying the BMI, may be a result of this limitation.

Our study has the following limitations: it is designed as an explorative retrospective study to identify potential adipose tissue parameters with influence on the most common types of surgical and medical complication after RC surgery. Because of the limited number of overall patients and complication events in our study collective, the clinical relevance of our significant findings needs to be validated. To further investigate the relevance of the above-mentioned findings and the associations of the adipose tissue compartments with rarer complications, higher overall patient numbers are needed to avoid potential errors of multiple testing. In 153 of 296 cases, patients were entirely within the field of view (FOV) of the CT scanner, allowing for documentation of all parameters. In another 101 patients, the L3/4 spinal level was completely within the FOV, enabling analysis of all parameters at L3/4 as well as pelvic and abdominal VAT, but not pelvic SAT. Forty-four patients were not entirely within the FOV of the CT scanner; thus, proper quantification of TAT and SAT in these patients was not possible. However, pelvic VAT was documented. We included CT scans of patients within 180 days from the surgery date to increase the number of patients included in this study. However, the mean time before and after surgery was 28 and 35 days, respectively (Table 1). This is a single-center study in a university hospital setting, with a potential patient selection bias. As a retrospective study, this study includes all documented complications, which occurred during the hospital stay. Later complications are not documented. Additionally, data of weight were collected using the anesthesia protocol of the date of surgery. There are no follow-up data of weight during the hospitalization time.

In conclusion, our study confirmed an obesity paradox with a protective effect of high adipose tissue regarding two types of complications (e.g., anastomotic leakages and overall surgical complications). On the other hand, we found an increase in complications in patients with high amounts of adipose tissue (e.g., wound infection, burst abdomen, bladder dysfunction, MC). However, BMI showed no influence on these complications. These findings show a more complex influence of body composition on MC and SC. CT-quantified obesity is able to provide deeper insights to explain the obesity paradox beyond BMI. 


\section{Acknowledgements}

Johanna Nattenmüller was supported by a grant from the Medical Faculty of the University of Heidelberg.

\section{Statement of Ethics}

This retrospective study has been approved by the local institutional review board.

\section{Disclosure Statement}

The authors of this article declare no relationships with any companies, whose products or services may be related to the subject matter of the article.

\section{Funding Sources}

The authors state that this work has not received any funding.

\section{Author Contributions}

J.N. prepared the manuscript and had the primary responsibility for its final content. All authors critically revised the manuscript and approved its final content. A.B. evaluated the imaging and clinical data; J.B. and B.G. carried out the statistical analyses; A.B., J.B., J.N., M.S., A.U., C.M.U., H.U.K. designed the trial. C.M.U., M.S., Y.K., A.U. organized the trial and provided the data.

\section{References}

1 Haslam DW, James WP. Obesity. Lancet. 2005 Oct;366(9492):1197-209.

2 Renehan AG, Tyson M, Egger M, Heller RF, Zwahlen M. Body-mass index and incidence of cancer: a systematic review and meta-analysis of prospective observational studies. Lancet. 2008 Feb;371(9612):569-78.

3 Ng M, Fleming T, Robinson M, Thomson B, Graetz N, Margono C, et al. Global, regional, and national prevalence of overweight and obesity in children and adults during 1980-2013: a systematic analysis for the Global Burden of Disease Study 2013. Lancet. 2014 Aug;384(9945):766-81.

4 Calle EE, Thun MJ, Petrelli JM, Rodriguez C, Heath CW Jr. Body-mass index and mortality in a prospective cohort of U.S. adults. N Engl J Med. 1999 Oct;341(15):1097-105.

5 Berrington de Gonzalez A, Hartge P, Cerhan JR, Flint AJ, Hannan L, MacInnis RJ, et al. Body-mass index and mortality among 1.46 million white adults. N Engl J Med. 2010 Dec;363(23):2211-9.

6 Kalantar-Zadeh K, Block G, Horwich T, Fonarow GC. Reverse epidemiology of conventional cardiovascular risk factors in patients with chronic heart failure. J Am Coll Cardiol. 2004 Apr;43(8):1439-44.

7 Kalantar-Zadeh K, Block G, Humphreys MH, Kopple JD. Reverse epidemiology of cardiovascular risk factors in maintenance dialysis patients. Kidney Int. 2003 Mar;63(3):793-808.

8 Fleischmann E, Teal N, Dudley J, May W, Bower JD, Salahudeen AK. Influence of excess weight on mortality and hospital stay in 1346 hemodialysis patients. Kidney Int. 1999 Apr;55(4):1560-7.

9 Oreopoulos A, Padwal R, Kalantar-Zadeh K, Fonarow GC, Norris CM, McAlister FA. Body mass index and mortality in heart failure: a meta-analysis. Am Heart J. 2008 Jul;156(1):13-22.

10 Uretsky S, Messerli FH, Bangalore S, Champion A, Cooper-Dehoff RM, Zhou Q, et al. Obesity paradox in patients with hypertension and coronary artery disease. Am J Med. 2007 Oct;120(10):863-70.

11 Khalangot M, Tronko M, Kravchenko V, Kulchinska J, Hu G. Body mass index and the risk of total and cardiovascular mortality among patients with type 2 diabetes: a large prospective study in Ukraine. Heart. 2009 Mar; 95(6):454-60.

12 Mullen JT, Davenport DL, Hutter MM, Hosokawa PW, Henderson WG, Khuri SF, et al. Impact of body mass index on perioperative outcomes in patients undergoing major intra-abdominal cancer surgery. Ann Surg Oncol. 2008 Aug;15(8):2164-72.

13 Mullen JT, Moorman DW, Davenport DL. The obesity paradox: body mass index and outcomes in patients undergoing nonbariatric general surgery. Ann Surg. 2009 Jul;250(1):166-72. 
Nattenmüller et al.: The Obesity Paradox

14 Torre LA, Bray F, Siegel RL, Ferlay J, Lortet-Tieulent J, Jemal A. Global cancer statistics, 2012. CA Cancer J Clin. 2015 Mar;65(2):87-108.

15 Ma Y, Yang Y, Wang F, Zhang P, Shi C, Zou Y, et al. Obesity and risk of colorectal cancer: a systematic review of prospective studies. PLoS One. 2013;8(1):e53916.

16 Campbell PT, Newton CC, Dehal AN, Jacobs EJ, Patel AV, Gapstur SM. Impact of body mass index on survival after colorectal cancer diagnosis: the Cancer Prevention Study-II Nutrition Cohort. J Clin Oncol. 2012 Jan; 30(1):42-52.

17 Choi Y, Lee YH, Park SK, Cho H, Ahn KJ. Association between obesity and local control of advanced rectal cancer after combined surgery and radiotherapy. Radiat Oncol J. 2016 Jun;34(2):113-20.

18 Prado CM, Gonzalez MC, Heymsfield SB. Body composition phenotypes and obesity paradox. Curr Opin Clin Nutr Metab Care. 2015 Nov;18(6):535-51.

19 Irlbeck T, Massaro JM, Bamberg F, O’Donnell CJ, Hoffmann U, Fox CS. Association between single-slice measurements of visceral and abdominal subcutaneous adipose tissue with volumetric measurements: the Framingham Heart Study. Int J Obes. 2010 Apr;34(4):781-7.

20 Balentine CJ, Marshall C, Robinson C, Wilks J, Anaya D, Albo D, et al. Validating quantitative obesity measurements in colorectal cancer patients. J Surg Res. 2010 Nov;164(1):18-22.

21 Nattenmueller J, Hoegenauer H, Boehm J, Scherer D, Paskow M, Gigic B, et al. CT-based compartmental quantification of adipose tissue versus body metrics in colorectal cancer patients. Eur Radiol. 2016 Nov;26(11): 4131-40.

22 Sjöström L, Kvist H, Cederblad A, Tylén U. Determination of total adipose tissue and body fat in women by computed tomography, 40K, and tritium [doi]. Am J Physiol. 1986 Jun;250(6 Pt 1):E736-45.

23 Yoshizumi T, Nakamura T, Yamane M, Islam AH, Menju M, Yamasaki K, et al. Abdominal fat: standardized technique for measurement at CT. Radiology. 1999 Apr;211(1):283-6.

24 Balentine CJ, Wilks J, Robinson C, Marshall C, Anaya D, Albo D, et al. Obesity increases wound complications in rectal cancer surgery. J Surg Res. 2010 Sep;163(1):35-9.

25 Tsujinaka S, Konishi F, Kawamura YJ, Saito M, Tajima N, Tanaka O, et al. Visceral obesity predicts surgical outcomes after laparoscopic colectomy for sigmoid colon cancer. Dis Colon Rectum. 2008 Dec;51(12): 1757-65; discussion 1765-7.

26 Connelly TM, Juza RM, Sangster W, Sehgal R, Tappouni RF, Messaris E. Volumetric fat ratio and not body mass index is predictive of ileocolectomy outcomes in Crohn's disease patients. Dig Surg. 2014;31(3):219-24.

27 Lopez-Delgado JC, Esteve F, Manez R, Torrado H, Carrio ML, Rodríguez-Castro D, et al. The influence of body mass index on outcomes in patients undergoing cardiac surgery: does the obesity paradox really exist? PLoS One. 2015 Mar;10(3):e0118858.

28 Heus C, Cakir H, Lak A, Doodeman HJ, Houdijk AP. Visceral obesity, muscle mass and outcome in rectal cancer surgery after neo-adjuvant chemo-radiation. Int J Surg. 2016 May;29:159-64.

29 Chern H, Chou J, Donkor C, Shia J, Guillem JG, Nash GM, et al. Effects of obesity in rectal cancer surgery. J Am Coll Surg. 2010 Jul;211(1):55-60. 